\title{
Chromosome Pairing in the Interspecific Hybrids: Arachis hypogaea L. $X$ Arachis chacoense nom. nud. Krap et Greg. and A. hypogaea L. $X$ A. villosa Benth.
}

\author{
M. Bharathi, U. R. Murty, P. B. Kirti and N. G. P. Rao \\ Indian Agricultural Research Institute, Regional Station, \\ Rajendranagar, Hyderabad, India
}

Received September 9, 1981

The genus Arachis consists of 22 published species and 40 or more unpublished and a few unnamed species. These various taxa were grouped into seven sections (Gregory et al. 1973). Of these, the cultivated species $A$. hypogaea belongs to, and is crossable to, only the members of the section Arachis (Smartt and Gregory 1967, Gregory et al. 1973). This section consists of other than A. hypogaea and $A$. monticola (another tetraploid with $2 n=40)$; at least seven diploid species $(2 n=20)$ of which six carry the A genome (A. villosa, PI 219554; A. chacoense, PI 276235; $A$. correntina, PI 262808; A. duranensis, PI 219823; A. stenosperma; A. cardenasii, PI 262141) and one the B. genome; ( $A$. batizozoi, PI 338312). The A genome species contains the classical A chromosome of Husted (1931, '33, '36) while A. batizocoi does not have such a chromosome. A. hypogaea was assumed to have been derived as an amphiploid of an A and B genome species (Smartt et al. 1978). However, detailed studies on pachytene chromosome morphology by Murty and his coleagues (Murty et al. 1980, Murty et al. 1981, Murty et al. 1982, Kirti et al. 1982) have indicated that the probability of $A$. hypogaea to have been derived from two A-genome carrying species is as great as that from an A and a B genome species. The present investigation was undertaken to find out precise chromosome homologies ot two A genome species $A$. chacoense and $A$. villosa with those of $A$. hypogaea by studying detailed pachytene pairing in the triploid interspecific hybrids.

Plate I. Photomicrogarphs of the pachytene chromosomes of triploid intersepcific hybrids, $A$. hypogaea (TMV-2) $\times A$. chacoense $(2 n=30)$. Figs. $1-11$. 1 , long median chromosome (bivalent). 2 , long submedian chromosome (bivalent). 3, euchromosome (bivalent). 4, short median chromosome (bivalent). 5, nucleolus organizing chromosome (bivalent). 6 , chromosome with heterochromatic short arm (bivalent). 7, medium submedian chromosome (large unpaired regiouns are present). 8, medium median chromosome (bivalent). 9, short submedian chromosome (bivalent). 10, chromosome with heterochromatic short arm (bivalent). 11, A-chromosome (bivalent).

Plate II. Camera lucida drawings of the pachytene chromosomes of triploid interspecific hybrid, A. hypogaea $(\mathrm{TMV}-2) \times A$. chacoense $(2 n=30)$. Figs. 1-11. 1, long median chromosome (bivalent). 2, long submedian chromosome (bivalent). 3, euchromosome (bivalent). 4. short median chromosome (bivalent). 5, nuclelus organizing chromosome (bivalent). 6, chromosome with heterochromatic short arm (bivalent). 7, medium submedian chromosome (large unpaired regions are present). 8 , medium median chromosome (bivalent). 9, short submedian chromosome (bivalent). 10, chromosome with heterochromatic short arm (bivalent). 11, A- 

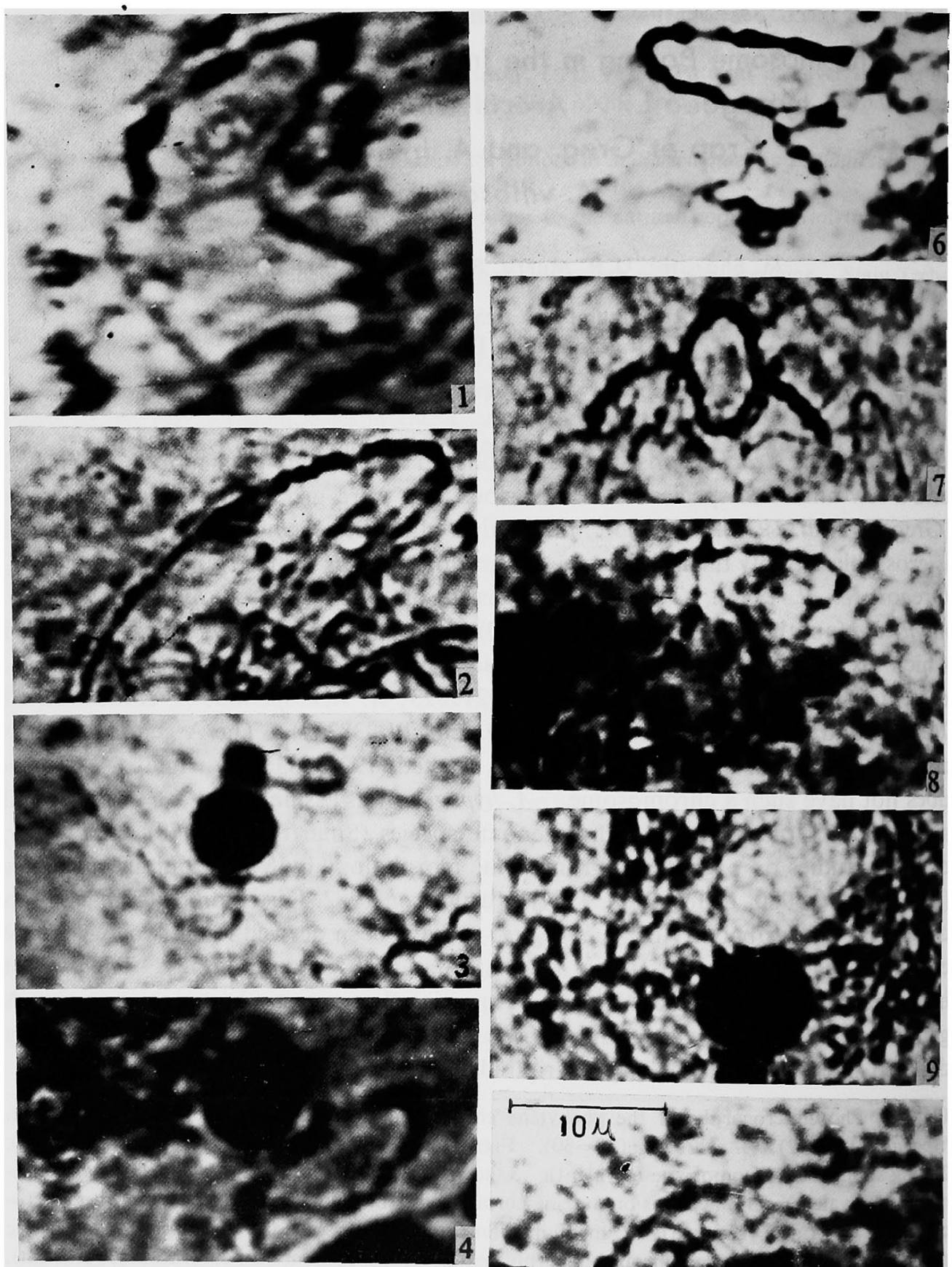

N.

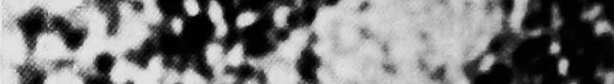

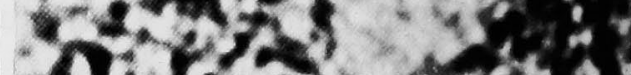
(1) 10y

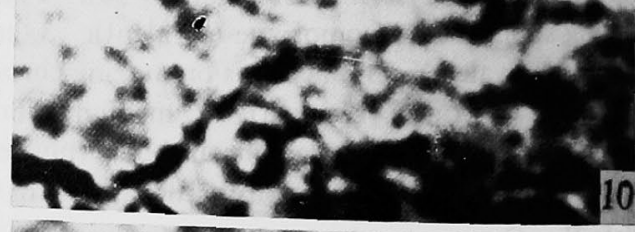

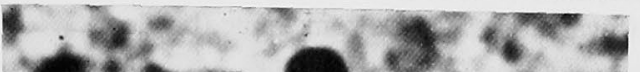
(6)

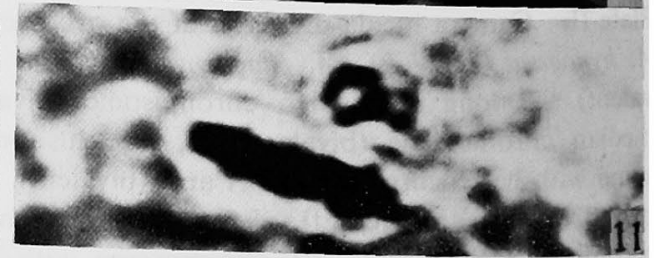



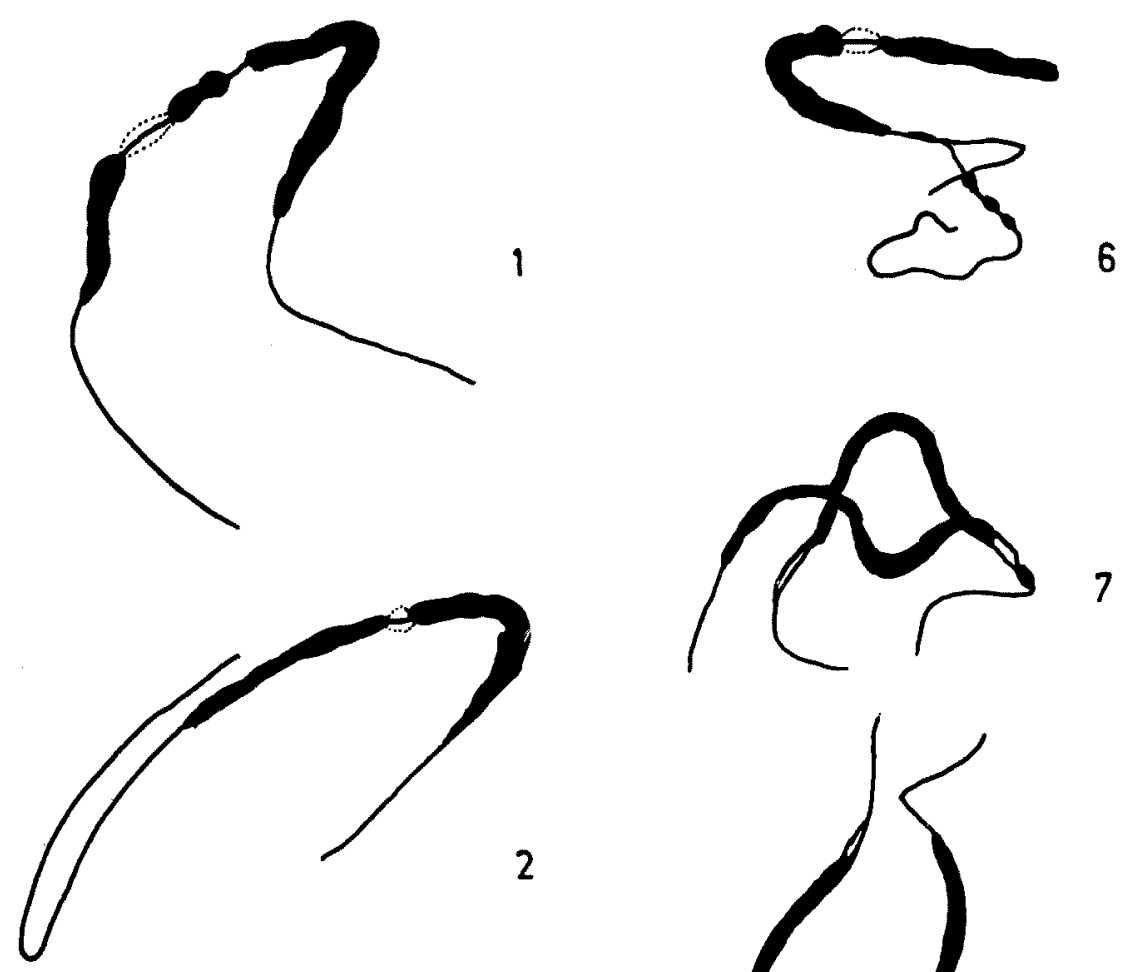

8
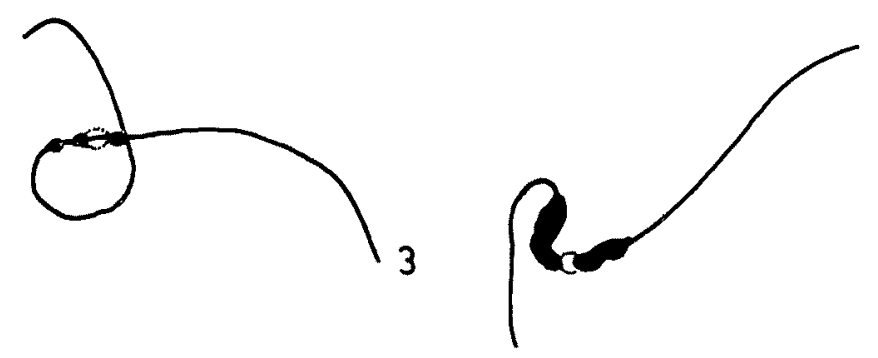

9
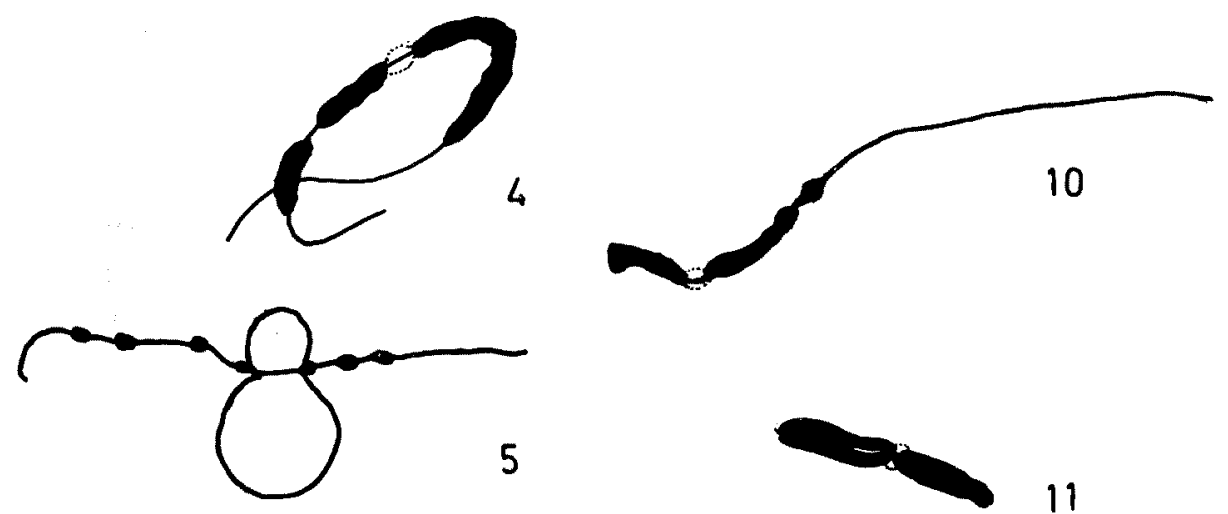

5

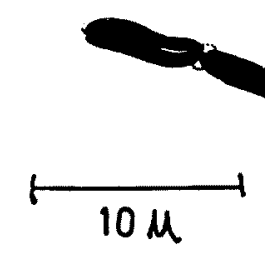

Plate II. 
Material and methods

The material consisted of a popular variety of groundnut, $\mathrm{TMV}_{2}$ and two diploid species $A$. chacoense PI 276235 and A. villosa PI 219554. A. chacoense was supplied by the cytogenetics section of ICRISAT and $A$. villosa by the Tamilnadu Agricultural University, Coimbatore.

Classical cytological techniques were used, details of which were given by Murty et al. $(1980,1982)$.

\section{Results}

In general, there was good amount of pairing resulting in bivalent formation. However, several chromosomes could be seen left unpaired and remaining as univalents (Pls. III and IV). Trivalents and quadrivalents also could be observed. It was not possible to analyse full chromosome complements from single pachytene nuclei. However, several thrown offs could be observed. From the pairing behaviour of the 10 chromosomes, the homologies of the 10 chromosomes of the diploid parent could be deduced. The details of the pairing behaviour of the chromosomes are given below. Details of the different chromosomes in A. hypogaea, A. chacoense and A. villosa are given in Murty et al. 1982 and Kirti et al. 1982.

1. Chromosome 1 of $A$. chacoense

This chrcmosome in $A$. chacoense is a long chromosome with a submedian centromere, measuring $63.33 \mu \mathrm{m}$. In the hybrid, it was seen to pair with chromosome 1 of $A$. hypogaea which is a long submedian chromosome with a total length of $60.5 \mu \mathrm{m}$. However, there was a small unpaired region in the heterochromatic region. (Pl. I, Fig. 2; Pl. II, Fig. 2).

2. Chromosome 2 of $A$. chacoense

This is a long median chromosome with a length of $51.80 \mu \mathrm{m}$. This chromosome was seen to pair with chromosome 2 of $A$. hypogaea in the hybrid. In $A$. hypogaea, this is a long median chromosome with a total length of $58.1 \mu \mathrm{m}$. These two chromosomes are seen to be completely homologous, pairing fully along their length except for a little unpaired region in one of the arms (PI. I, Fig. 1; Pl. II, Fig. 1).

3. Chromosome 3 of A. chacoense

This is a completely euchromatic chromosome having a total length of 42.05 $\mu \mathrm{m}$. This chromosome in the hybrid was seen to pair with chromosome 3 of $A$. hypogaea which is completely euchromatic measuring $52.1 \mu \mathrm{m}$ (Pl. I, Fig. 3; Pl. II, Fig. 3).

4. Chromosome 4 of $A$. chacoense

This is a medium sized chromosome wth a median centromere, measuring $36.83 \mu \mathrm{m}$. In the hybrid, it was seen to pair with chromosome 9 of $A$. hypogaea which is also a medium sized chromosome with a median centromere having a total length of $31.3 \mu \mathrm{M}$. However this pairing is partial, there being a long unpaired region in one of the arms (PI. I, Fig. 8; PI. II, Fig. 8). 
5. Chromosome 5 of $A$. chacoense

This is a medium sized submedian chromosome having a total length of 35.55 $\mu \mathrm{m}$. This chromosome in the hybrid is seen to pair with chromosome 8 of $A$. hypogaea which is a medium sized chromosome with a submedian centromere and length of $32.51 \mu \mathrm{m}$ (PI. I, Fig. 7; Pl. II, Fig. 7).

6. Chromosome 6 of $A$. chacoense

This is a short chromosome with a median centromere. It is having a total length of $28.55 \mu \mathrm{m}$. This chromosome in the hybrid was seen to pair with chromosome 15 of $A$. hypogaea (PI. I, Fig. 4; Pl. II, Fig. 4).

7. Chromosome 7 of $A$. chacoense

This is a short submedian chromosome with a total length of $26.13 \mu \mathrm{m}$. In the hybrid, this chromosome was seen to pair with chromosome 16 , which is short and submedian with a length of $24.0 \mu \mathrm{m}$ in $A$. hypogaea. These two chromosomes are seen to pair completely in the hybrid (PI. I, Fig. 9; Pl. II, Fig. 9).

8. Chromosome 8 of $A$. chacoense

This is the nucleolus organizing chromosome having a length of $24.00 \mu \mathrm{m}$. This chromosome is completely homologous to the 12th chromosome of A. hypogaea which is also a nucleolus organizing chromosome with a total length of 28.8 $\mu \mathrm{m}$. These two chromosomes in the hybrid were seen to pair completely with each other (Pl. I, Fig. 5; Pl. II, Fig. 5).

9. Chromosome 9 of $A$. chacoense

It is a chromosome with completely heterochromatic short arm with a total length of $23.50 \mu \mathrm{m}$. This chromosome in the hybrid was seen to pair with chromosome 14, which is a long chromosome with completely heterochromatic short arm with a length of $25.7 \mu \mathrm{m}$ of $A$. hypogaea (Pl. I, Fig. 10; Pl. II, Fig. 10). However, in some PMCs it was observed that this chromosome also paired with chromosome 19 of $A$. hypogaea, which also has a hetero chromatic short arm with a total length of $15.4 \mu \mathrm{m}$. These chromosomes pair completely in the hetreochromatic region, the euchromatic region, however, remained unpaired (Pl. I, Fig. 6; Pl. II, Fig. 6). 10. Chromosome 10 of A. chacoense

This is the shortest chromosome of the set, which is completely heterochromatic. This chromosome has a total length of $14.58 \mu \mathrm{m}$ and represents the ' $\mathrm{A}$ ' chromosome. This is completely homologous with chromosome 20 of $A$. hypogaea. These two chromosomes were seen to pair completely in the hybrid (Pl. I, Fig.11; Pl. II, Fig. 11).

Although multivalents, like trivalents and quadrivalents were observed, they could not be identified accurately because of the extensive clumping of the chromosomes.

\section{B. A. hypogaea $\times$ A. villosa}

1. Chromosome 1 of $A$. villosa

This chromosome in $A$. villosa is a long submedian chromosome having a total length of $60.99 \mu \mathrm{m}$. In the hybrid this chromosome was seen to pair with chromosome 1 of $A$. hypogaea which is a long chromosome with a submedian centromere having a total length of $60.5 \mu \mathrm{m}$. However, some unpaired regions were ob- 
served occasionally (P1. V, Fig. 2; Pl. VI, Fig. 2).

2. Chromosome 2 of $A$. villosa

This is a long chromosome with a median centromere, with a total length of $46.02 \mu \mathrm{m}$. This chromosome in the hybrid was seen to pair with chromosome 5 of A. hypogaea which is a long median chromosome having a total length of $42.0 \mu \mathrm{m}$ (Pl. V, Fig. 1; Pl. VI, Fig. 1).

3. Chromosome 3 of $A$. villosa

This is a medium sized chromosome with a submedian centromere with a total length of 37.50 $\mu \mathrm{m}$. This chromosome in the hybrid was seen to pair with chromosome 7 of $A$. hypogaea which is a medium submedian chromosome having a total length of $31.8 \mu \mathrm{m}$ (Pl. V, Fig. 3 (left); Pl. VI, Fig. 3). 4. Chromosome 4 of $A$. villosa

This is a medium sized chromosome with a median centromere. In the hybrid this chromosome was seen to pair with chromosome 9 of $A$. hypogaea. In this chromosome pair, a small unpaired region was observed in the long arm (P1. V, Fig. 4; Pl. VI, Fig. 4).

Plate III. Photomicrographs of the pachytene chromosomes of triploid interspecific hybrid, $A$. hypogaea (TMV$2) \times A$. chacoense $(2 n=30)$. Figs. $1-5$. 1, long submedian chromosome (I). 2, medium median chromosome (II). 3, long medium chromosome (I), 4, medium submedian chromosome (II). 5 , chromosome with heterochromatic short arm (I).
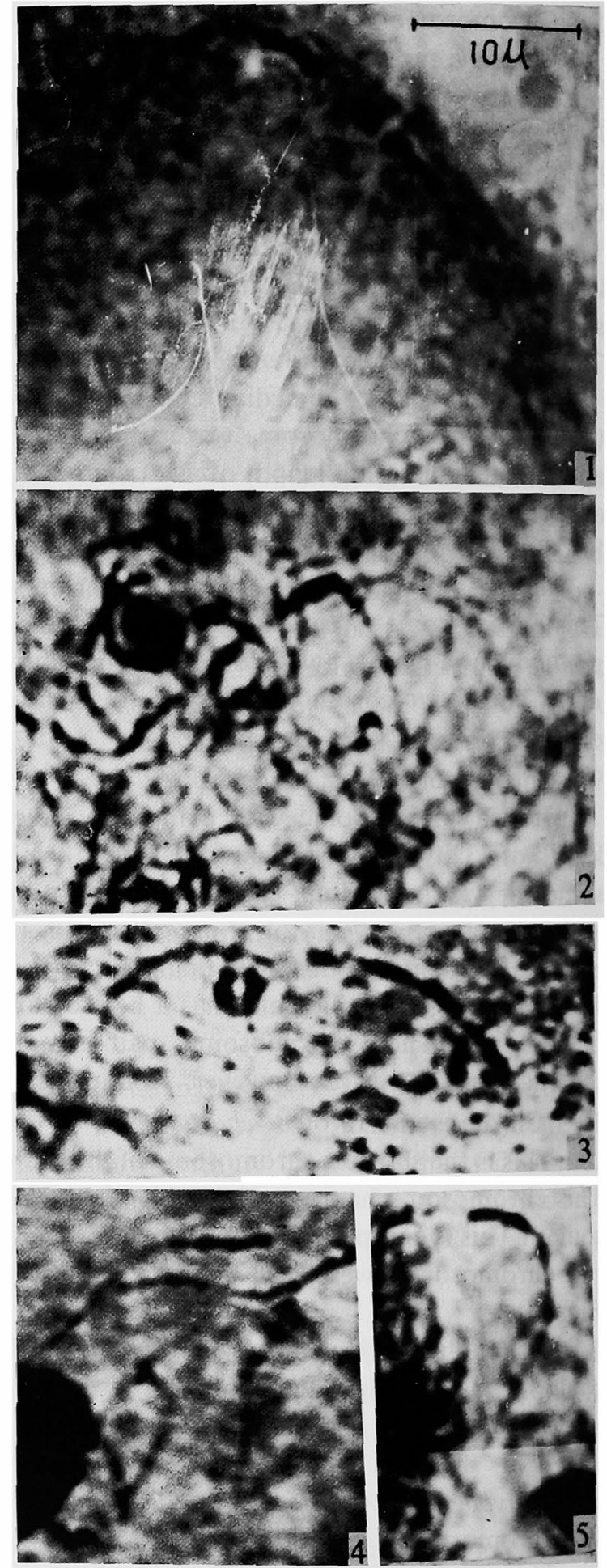

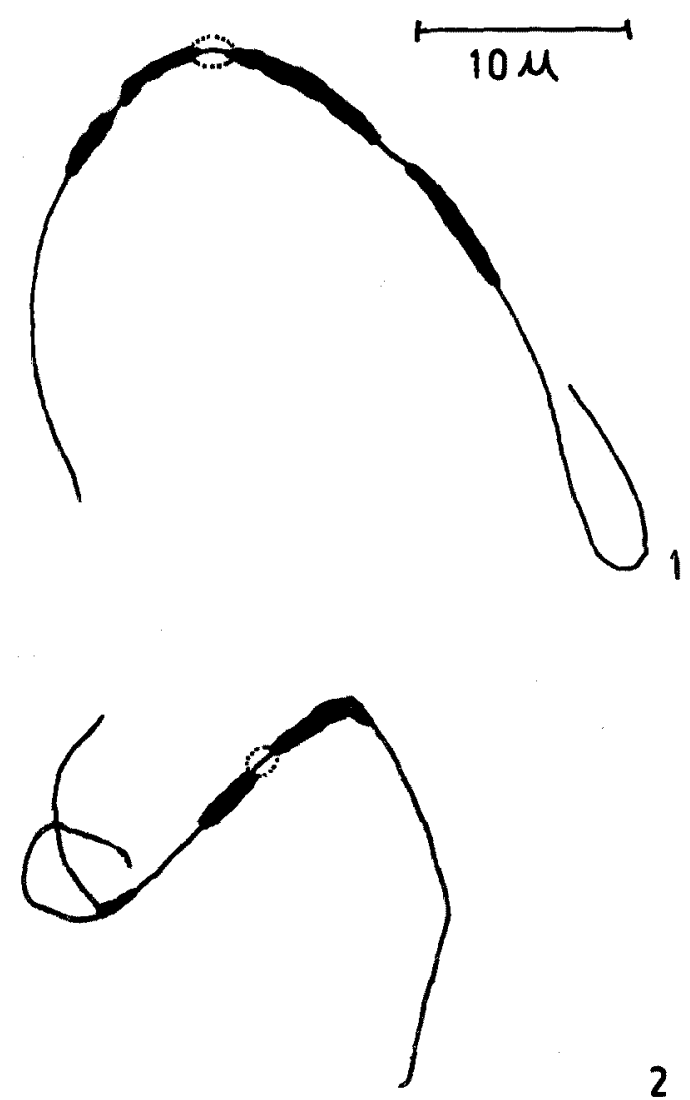

2
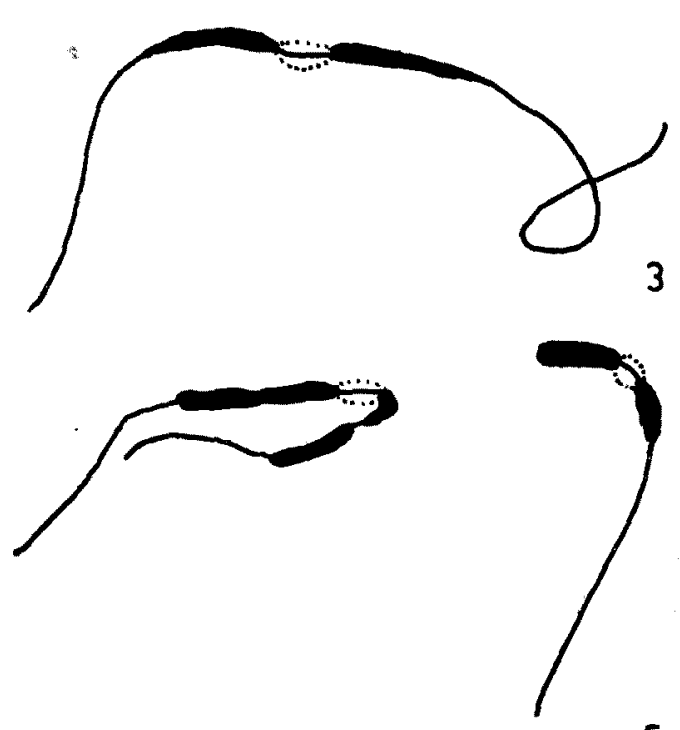

4
5. Chromosome 5 of A. villosa

This is a short chromosome with a median centromere, with a total length of $25.30 \mu \mathrm{m}$. This chromosome in the hybrid was seen to pair with chromosome 16 of $A$. hypogaea, which is a short median chromosome measuring $24.9 \mu \mathrm{m}$ (Pl. V, Fig. 5; (Bottom) Pl. VI, Fig. 5).

6. Chromosome 6 of $A$. villosa

This is a short chromosome with a submedian centromere, measuring $24.0 \mu \mathrm{m}$. In the hybrid this chromosome was seen to pair with chromosome 15 of A. hypogaea. In this chromosome pair, a small unpaired region was observed in the long arm (Pl. V, Fig. 7; Pl. VI, Fig. 7).

7. Chromosome 7 of $A$. villosa

This is a euchromosome, with a total length of $23.56 \mu \mathrm{m}$. This chromosome in the hybrid was seen to pair with chromosome 11 of $A$. hypogaea (Pl. V, Fig. 3 (right); PI. VI, Fig. 3).

8. Chromosome 8 of A. villosa

This is a chromosome with a completely hetrochromatic short arm, measuring $19.83 \mu \mathrm{m}$. This

Plate IV. Camera lucida drawings of the pachytene chromosomes of triploid interspecific hybrid, A. hypogaea (TMV2) $\times A$. chacoense $(2 n=30)$. Figs. $1-5$. 1, long submedian chromosome (I). 2, medium median chromosome (II). 3, long median chromosome (I). 4, medium submedian chromosome (I). 5, chromosome with heterochromatic short arm (I). 


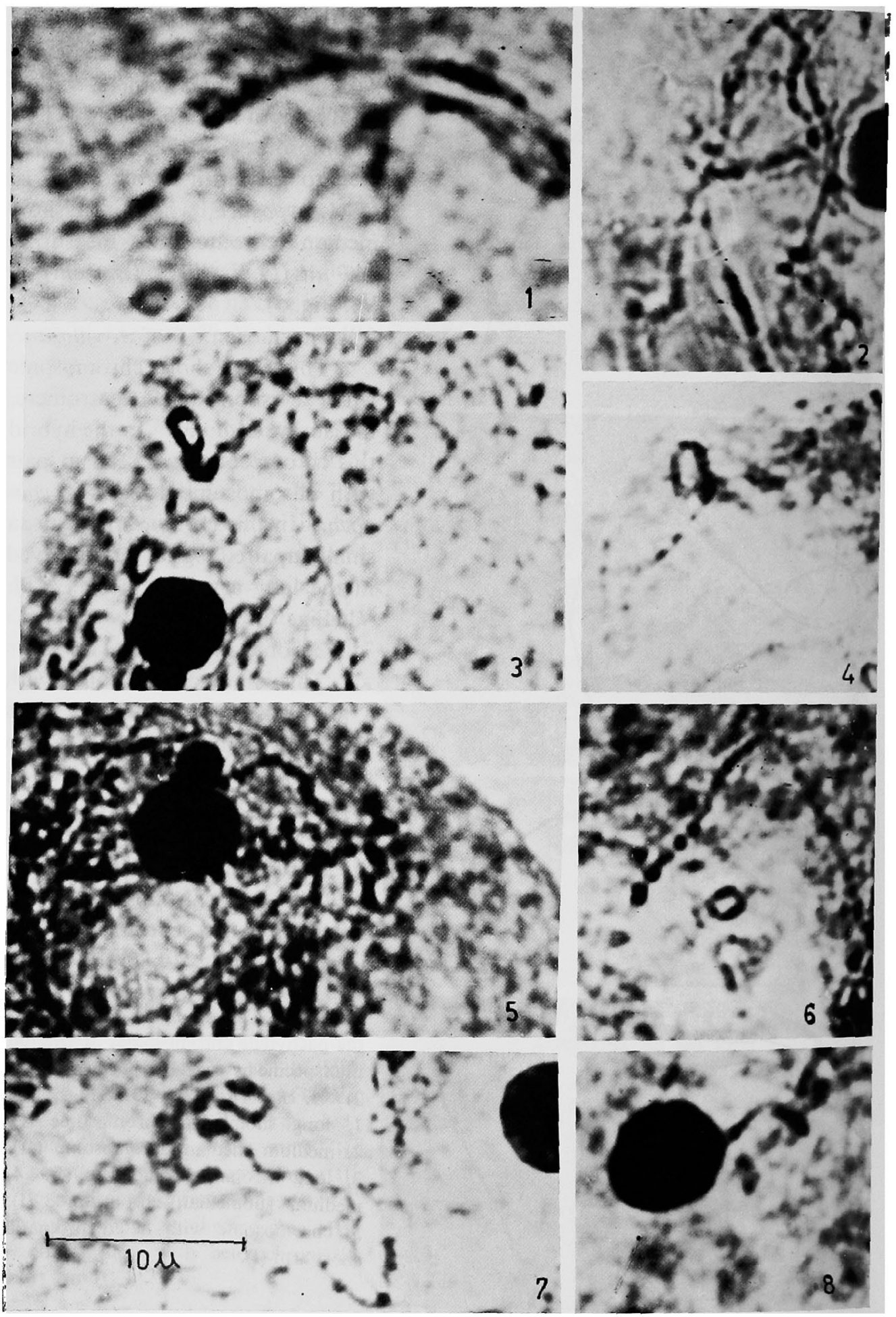

Plate V. Photomicrographs of the pachytene chromosomes of triploid interspecific hybrid, $A$. hypogaea $(\mathrm{TMV}-2) \times A$. villosa. Figs. 1-8. 1, long median chromosome (bivalent). 2, long submedian chromosome (bivalant). 3, euchomosome (bivalent) (right); medium submedian chromosome (bivalent) (left). 4, medium median chromosome (bivalent). 5, nucleolus organizing chromosome (bivalent) (top); short median chromosome (bivalent) (bottom). 6, chromosome with heterochromatic short arm (bivalent). 7, short submedian chromosome (bivalent). 8, Achromosome (bivalent). 

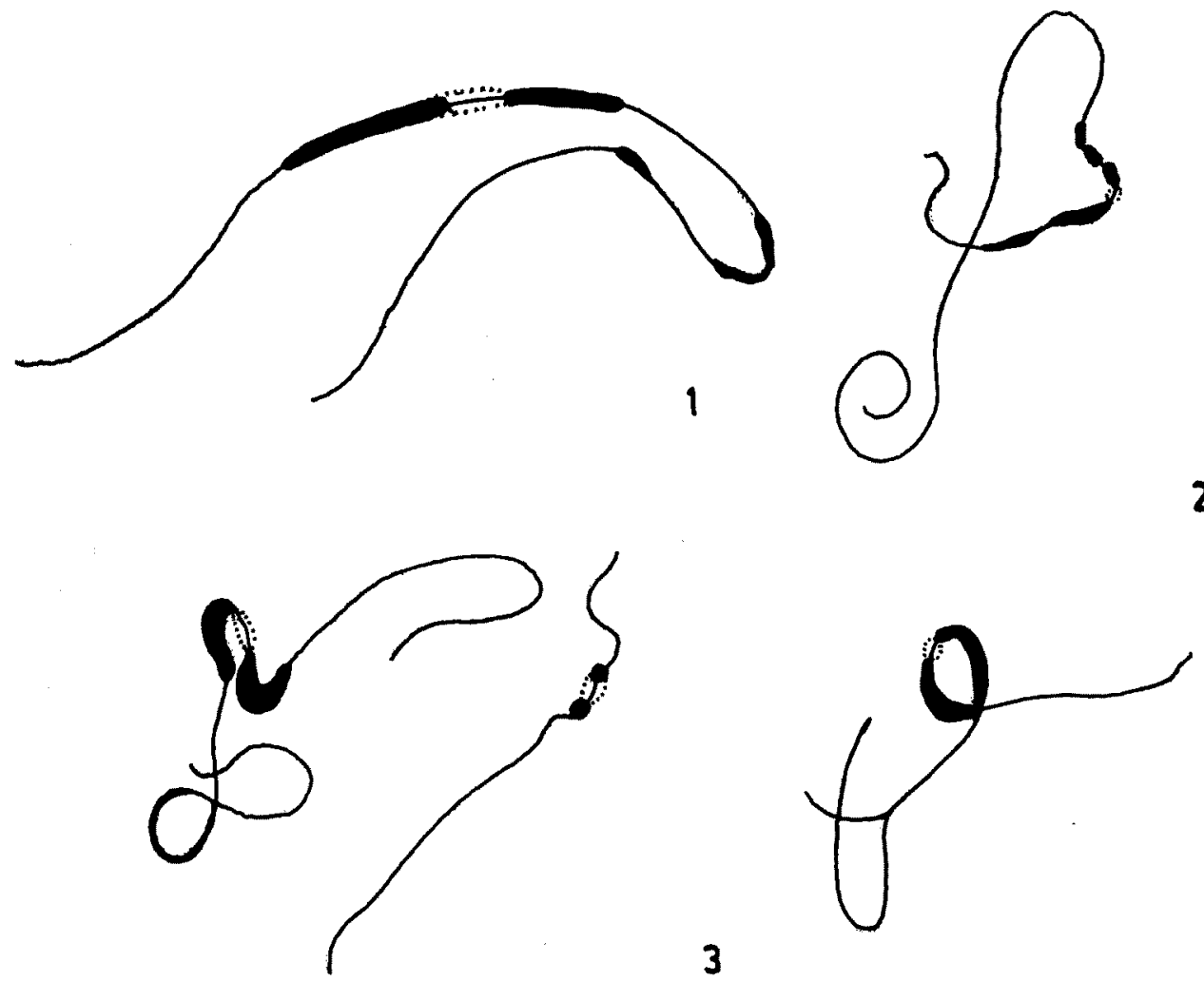

3
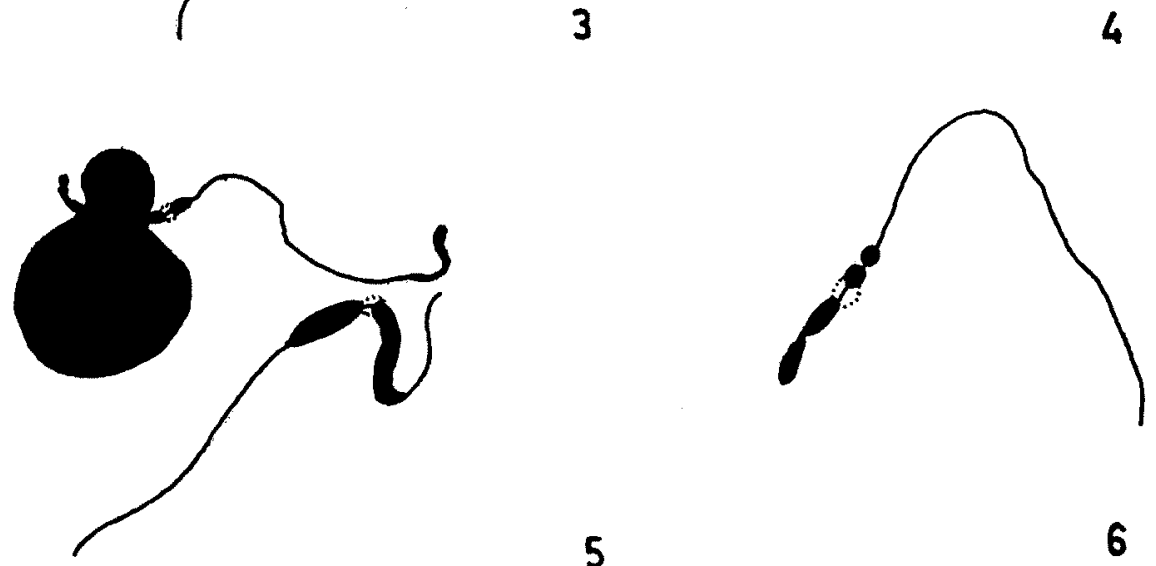

5

6
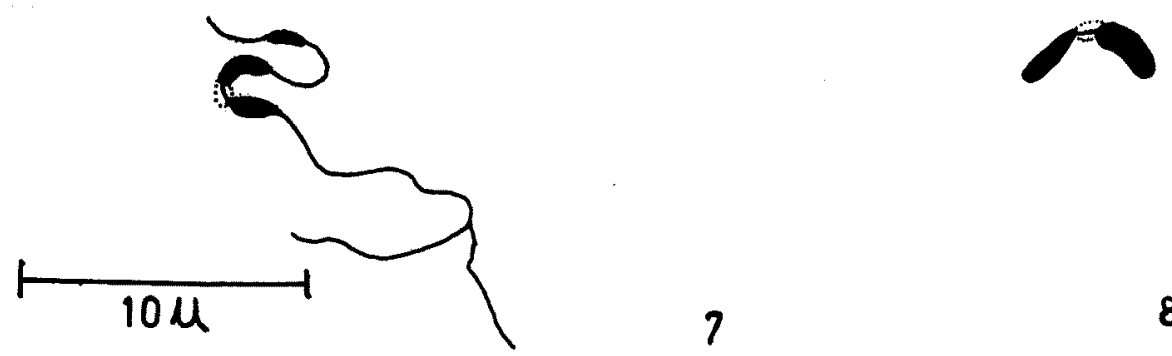

Plate VI. Camera lucida drawing of the pachytene chromosome of triploid interspecific hybrid, A. hypogaea (TMV-2) $\times$ A. villosa. Figs. 1-8. 1, long median chromosome (bivalent). 2, long submedian chromosome (bivalent). 3, euchromosome (bivalent) (right); medium submedian chromosome (bivalent) (left). 4, medium median chromosome (bivalent). 5, nucleous organizing chromosome (bivalent) (top); short median chromosome (bivalent) (bottom). 6, chromosome with heterochromatic short arm (bivalent). 7, short submedian chromosome (bivalent). 8, A- chromosome (bivalent) 
chromosome in the hybrid was seen to pair with chromosome 19 of $A$. hypogaea, which is the second (short) chromosome with completely heterochromatic short arm, with a total length of $15.4 \mu \mathrm{m}$ (Pl. V, Fig. 6; Pl. VI, Fig. 6).

9. Chromosome 9 of $A$, villosa

This is a nucleolus organising chromosome with a total length of $15.56 \mu \mathrm{m}$. This chromosome has a nucleolus organizing region in the submedian position. In the hybrid, the chromosome was seen to pair with chromosome 13 of $A$. hypogaea (Pl. V, Fig. 5 (top); Pl. VI, Fig. 5).

10. Chromosome 10 of $A$. villosa

This is the A-chromosome. It has a total length of $12.14 \mu \mathrm{m}$. The Achromosomes of both the species paired perfectly. The length difference measured in individual species was seen to disappear in the hybrid (Pl. V, Fig. 8; PI. VI, Fig. 8).

\section{Discussion}

A. hypogaea contains two genomes, the A and the B. Although several A genome species were identified among the section Arachis, there is only one Bgenome species, i.e. A. batizocoi. Murty et al. (1980) characterised the A-genome as consisting of the A-chromosome; a chromosome with completely heterochromatic short arm; a euchromosome; a nucleolus organizer; 2 long chromosomes; 2 medium and 2 short chromosomes. Each of these chromosomes could be distinguished on the basis of centromere position. The B-genome was characterized as consisting of the B-chromosome (chromosome with 2 large heterochromatin blocks in short arm); a chromosome with completely heterochromatic short arm; a euchromosome; a nucleolus organizer; the long median, the long submedian, the medium median, the medium submedian, the short median and the short submedian chromosomes. The genomes of $A$. villosa and $A$. chacoense compared more or less with the A-genome. However, A. villosa differs from $A$. chacoense in the morphology of the nucleolus organizer. $A$. hypogaea has two nucleolus organizer chromosomes each of them pairing with the corresponding nucleolus organizing chromosomes of $A$. villosa and $A$. chacoense.

The genomes of $A$. hypogaea have been much discussed. The presence of occasional quadrivalents and the presence of a single pair of A-chromosomes have led to the designation of $A$. hypogaea as a segmental allotetraploid (Stebbins 1957). One or the other of the ' $\mathrm{A}$ ' genome species has been suggested as at least one of the putative parents of $A$. hypogaea by several workers from time to time (Varisai Muhammed 1973, Seetaram et al. 1973, Gregory and Gregory 1976, Smart et al. 1978). Ressler et al. (1981) concluded from their studies on estimations of DNA, that it may not be possible to identify the genomes of $A$. hypogaea. However, pachytene analysis has given some concrete information on this point.

Chromosome pairing results of the present investigation suggest that both $A$. villosa or $A$. chacoense although have homologous partners in $A$. hypogaea, have minor structural differences in the form of unpaired regions and heteromorphic bivalents. Reports of chromosome pairing in the hybrid between A and B genome 
species (Stalker and Wynne 1979) suggest that A. batizocoi has at least 8 chromosomes homologous with those of the A-genome species. If the chromosomes of $A$. chacoense and $A$. villosa paired predominantly with the A-genome of $A$. hypogaea and if the other chromosomes of A. hypogaea originated from A. batizocoi, then one should expect at least 8 trivalents in such hybrids. Non occurrence of such a high frequency of trivalents suggests 3 possibilities.

1. That the B-genome of $A$. hypogaea may not be from A. batizocoi.

2. There is preferential pairing between homeologous chromosomes.

3. Extensive structural alterations leading to the differentiation of $\mathbf{A}$ and $\mathbf{B}$ genomes.

From this discussion it is apparent that the classification of the genomes of $A$. hypogaea into $\mathrm{A}$ and $\mathrm{B}$ is only tentative. There is extensive structural repatterning in the A-genome species. There are evidences for structural changes in the genomes of $A$. hypogaea also so as to result in predominant bivalent formation. Evidence for concluding structural alterations was obtained from the occasional presence of unpaired regions and heteromorphic bivalents.

\section{Summary}

Chromosome pairing at the pachytene stage of meiosis was studied in triploid hybrids involving $A$. hypogaea, and $A$. chacoense and $A$. villosa. There was very good pairing at least in respect of 10 chromosomes. Unpaired regions and heteromorphic bivalents were observed occasionally. Chromosome pairing indicated a close relation among the 3 species. A. hypogaea has 10 chromosomes in common with $A$. chacoense and $A$. villosa although the 10 chromosomes of each these species are not necessarily homologous. Evidence was obtained for the existence of structural repatterning in the A-genome species and also in the genomes of $A$. hypogaea. The information obtained was utilised in the discussion of the origin of $A$. hypogaea.

\section{Acknowledgement}

This investigation was carried out under a special National Research Scheme for solving basic problems related to the productivity of groundnut. The authors are thankful to ICAR for the same. Grateful thanks are also due to Dr. H. K. Jain, O. P. Gautam and M.S. Swaminathan for their interest and encouragement.

\section{References}

Gregory, W. C., Gregory, M. P., Krapovickas, A., Smith, W. B. and Yarbrough, J. A. 1973. Structures and genetic resources of peanuts. In Peanuts-Culture and Uses, pp. 41-133. APREA Inc. Stone Printing Co., Virginia.

- and - 1976. Groundnuts: Arachis hypogaea, Leguminosae-Papilionatae, pp. 151-154. In N. W. Simmonds (ed.): Evolution of Crop Plants. Longman Group Ltd., London, England.

Husted, L. 1931. Chromosome numbers in species of peanut, Arachis. Amer. Nat. 65:476-477. 
- 1933. Cytological studies on peanut, Arachis I. Chromosome number and morphology. Cytologia 5 : 109-117.

- 1936. Cytological studies on the peanut, Arachis II. Chromosome number and morphology and behaviour and their application to the problem of origin of cultivated forms. Cytologia $7: 396-423$.

Kirti, P. B., Bharathi, M., Murty, U. R. and Rao, N. G. P. 1983. Chromosome morphology in 3 wild species of Arachis and their bearing on the genomes of Arachis hypogaea. Cytologia 48: 139-151.

Murty, U. R., Kirti, P. B., Bharathi, M. and Rao, N. G. P. 1980. Chromosome morphology in groundnut, Arachis hypogaea L. Proc. National Symposium on the application of genetics in the improvement of groundnut. Tamilnadu, Agricultural University, Coimbatore, India.

-, Rao, N. G. P., Kirti, P. .B and Bharathi, M. 1981. Cytogenetics and groundnut improvement. Report of the research project "cytogenetic studies of Arachis with special reference to application in breeding" scheme for the creation of professorial chairs. Indian Council of Agricultural Research. pp. 1-25, Plates 3, Ref. 6 pp.

-, Kirti, P. B., Bharathi, M. and Rao, N. G. P. 1982. The identification of the chromosomes in groundnut, Arachis hypogaea L. Cytologia 47: 585-594.

Ressler, P. M., Stucky, J. M. and Miksche, J. P. 1981. Cytophotometric determination of the amount of DNA in Arachis L. Sect. Arachis. Amer. J. Bot. 68: 149-153.

Seetaram, A., Nayar, K. D. M., Sreekantarahyal, R. and Achar, D. K. T. 1973. Cytological studies on interspecific hybrids of Arachis hypogaea $\times$ Arachis duranensis. Cytologia 38: 277-280.

Smartt, J. and Gregory, W. C. 1967. Interspecific cross compatibility between the cultivated peanut, Arachis hypogciea L. I. Cytogenetic studies of putative genomes donors. Euphytica 27: $665-675$.

Stalker, H. T. and Wynne, J. C. 1979. Cytology of interspecific hybrids in section Arachis of peanuts. Peanut Science 6: 110-114.

Stebbins, G. L. 1957. Genetics, evolution and plant breeding. Indian Jour. Genet. Plant Breeding 17: 129-141.

Varisai Muhammed, S. 1973. Cytological investigations in the genus Arachis II. Triploid hybrids and their derivatives. Madras. Agril. Jour. 60: 1414-1427. 